\title{
EDITORIAL \\ Impact of COVID-19 on neurosurgery resident training and education
}

\author{
Nicholas C. Bambakidis, MD, and Krystal L. Tomei, MD, MPH \\ Department of Neurological Surgery, University Hospitals Cleveland Medical Center, Cleveland, Ohio
}

$\mathrm{O}$ January 20, 2020, the first confirmed case of COVID-19 in the US was reported in Washington State. By March 13, with over 2700 cases confirmed in the US, the American College of Surgeons recommended the cessation of elective surgeries. "Social distancing" became common lingo, and large gatherings, including educational conferences, were abruptly canceled. Medical students were pulled off rotations to protect them from exposure and preserve personal protective equipment (PPE). Over the following weeks, most hospitals reduced their nonessential surgery volume, performing only surgeries that were emergent, urgent, or time sensitive. One week later, more than 25,000 COVID-19 cases were confirmed, present in all 50 states. The rapid evolution of healthcare delivery into telehealth and telephonebased models changed our clinical landscape drastically. Normal inpatient volumes decreased as hospitals prepared for the surge of COVID-19 cases and potential redeployment of physicians into areas of need. We adapted rapidly. However, this was only part of the challenge that academic hospitals would face.

Those of us at teaching hospitals must balance priorities between patient care and resident education. Critical to training the next generation of neurosurgeons is a combination of didactic conferences and experiences as well as hands-on surgical education. When in-person didactics are canceled and surgical volume is significantly reduced, how does a program adapt education rapidly? In addition, with increasing concern for an inadequate supply of PPE, how do we as educators protect our residents from harm while knowing that their knowledge, experience, and grit are exactly what is necessary to help the medical workforce during this crisis?

Only once in recent history has such a pandemic impacted medical education-the severe acute respiratory syndrome (SARS) pandemic in 2003. Published experiences out of Hong Kong, Singapore, and Toronto represent some of the only accounts of the effect on medical education. In March 2003, both medical schools in Hong Kong were forced to abruptly transition undergraduate medical education into a recorded lecture format, and students were taken out of clinical rotations until the new cases had ceased. ${ }^{1}$ One month later, the University of Toronto suspended student education in teaching hospitals. ${ }^{2}$ Singapore reflected on this opportunity to embrace technological advances in web-based learning and simulation but also noted the importance in training medical students in the use of PPE. ${ }^{3} \mathrm{~A}$ rare perspective on how such an epidemic impacted resident training was written by Sherbino and Atzema in 2004. ${ }^{4}$ Their account as residents in the emergency department at the University of Toronto highlights the impact on resident education. As with the current pandemic, elective cases were halted, staff was screened for fevers and symptoms at the entrance, out-ofcity electives were postponed, and in-person conferences were eliminated. Their altered educational experience spanned one-third of the academic year.

Our current situation is plagued with another grim reality - the sheer volume of patients and the inadequate supply of PPE to keep everyone safe have significantly altered training. The Association of American Medical Colleges (AAMC) issued a statement recommending suspension of medical student-patient contact. ${ }^{5}$ The Accreditation Council for Graduate Medical Education (ACGME) reiterated that residents who are managing suspected or confirmed COVID-19 cases should have adequate supervision by faculty who are trained in such protocols, which may impact the availability of supervision. ${ }^{6}$ The American Board of Medical Specialties issued a statement that it does not want trainees punished for situations beyond their control and urged the boards to consider this as well. ${ }^{7}$ The American Board of Neurological Surgery has postponed both primary and oral examinations.

We had the opportunity to gather from several programs information about the impact of COVID-19 on operative volume, modifications to resident rotations to ensure maintenance of a healthy workforce, and alterations in resident didactic opportunities. Most programs have seen a significant drop in elective or nonessential surgical volume, impacting the functional neurosurgery cases foremost. Unruptured aneurysm surgery, spine surgery, benign tumors, and other less urgent surgical cases have 
been postponed. New information on the particular risk of nasopharyngeal cases with virus shedding has caused many centers to reconsider offering endonasal surgery. Several centers are only continuing with neurosurgical emergencies that are typically limited to neurotrauma, shunts, stroke, malignant tumors, and cord compression. Naturally, patients with aneurysmal subarachnoid hemorrhage require treatment as well. In addition, surgeries that will allow patients to leave the hospital continue. Overall, programs report a significant decrease in the volume of cases. Clinic visits have transitioned to telemedicine where possible, decreasing resident exposure to outpatient encounters.

With the decrease in cases, programs have been able to transition their resident coverage models to reduce resident exposure and risk, while also allowing for backup options should any residents fall ill or come under quarantine. Many programs report decreasing resident staffing to $50 \%$ of normal, allowing teams to rotate on for a week at a time, while keeping the remainder of the residents at home and away from exposure. Surgical cases are limited to a single resident to preserve PPE. Resident rounds include only the necessary personnel in person, and communication is largely moving to electronic forms. Mitigating exposure risk has extended to resident conferences with many programs reporting a transition to virtual conferences by using videoconference technology and holding more frequent sessions to compensate for decreased operative case exposure. A joint statement from the presidents of the Congress of Neurological Surgeons (CNS) and the American Association of Neurological Surgeons mentions the plans for available online education to be rolled out in the coming months, and in fact the CNS just started a Virtual Visiting Professor program as part of this initiative.

As neurosurgeons, we have been a community known for resilience, grit, determination, and academic curiosity. Programs have been forced to make drastic and rapid changes in medical education that highlight our flexibility and determination to provide our residents with the best possible education despite extenuating circumstances. Certainly, once this pandemic has concluded, careful retrospective analysis of its impact on resident case volume will be necessary to ensure we are prepared for any future events. In addition, sharing best practices and the willingness of the neurosurgical community at large to step up and provide openly accessible education highlights our dedication to ensuring that we continue to train neurosurgeons of the next generation.

https://thejns.org/doi/abs/10.3171/2020.3.JNS20965

\section{Acknowledgments}

We would like to thank the following individuals who provided information on resident training impact: Sepideh AminHanjani, Daniel Eichberg, Richard Ellenbogen, Ricardo Komotar, Allan Levi, Brian Nahed, Julie Pilitsis, and Ciaran Powers. We would also like to thank the following contributors: Daniel K. Resnick, Nader S. Dahdaleh, Tony Asher, and Gerald Grant.

\section{References}

1. Patil NG, Chan Y, Yan H. SARS and its effect on medical education in Hong Kong. Med Educ. 2003;37(12):1127-1128.

2. Clark J. Fear of SARS thwarts medical education in Toronto. BMJ. 2003;326(7393):784.

3. Lim EC, Oh VM, Koh DR, Seet RC. The challenges of "continuing medical education" in a pandemic era. Ann Acad Med Singapore. 2009;38(8):724-726.

4. Sherbino J, Atzema C. "SARS-Ed": severe acute respiratory syndrome and the impact on medical education. Ann Emerg Med. 2004;44(3):229-231.

5. Whelan A, Prescott J, Young G, Catanese V. Guidance on medical students' clinical participation: effective immediately. March 17, 2020. AAMC. Accessed March 31, 2020. https://www.aamc.org/system/files/2020-03/ Guidance\%20on\%20Student $\% 20$ Clinical $\% 20$ Participation\%203.17.20\%20Final.pdf

6. ACGME Guidance Statement on Coronavirus (COVID-19) and Resident/Fellow Education and Training Considerations. March 6, 2020. ACGME. Accessed March 31, 2020.

https://www.acgme.org/newsroom/newsroom-details/ articleid/10068/acgme-guidance-statement-on-coronaviruscovid-19-and-resident-fellow-education-and-trainingconsiderations

7. ABMS Statement to DIOs Regarding Coronavirus Disease 2019 (COVID-19). March 13, 2020. ABMS. Accessed March 31, 2020. https://acgme.org/Newsroom/Newsroom-Details/ ArticleID/10085/ACGME-Resident-Fellow-Education-andTraining-Considerations-related-to-Coronavirus-COVID-19

\section{Disclosures}

The authors report no conflict of interest.

\section{Correspondence}

Nicholas C. Bambakidis: nicholas.bambakidis2@uhhospitals.org.

INCLUDE WHEN CITING

Published online April 17, 2020; DOI: 10.3171/2020.3.JNS20965. 